\title{
A Simulation-Based Tool to Support Decision-Making in Logistics Design of a Can Packaging Line
}

\author{
${ }^{1}$ INTEC (UNL-CONICET), Güemes 3450, Santa Fe 3000, Argentina, E-mail: vachkar@intec.unl.edu.ar, \\ cmendez@intec.unl.edu.ar. https://orcid.org/0000-0001-6268-0118. \\ ${ }^{2}$ Facultad de Ingenieria Quimica, Universidad Nacional del Litoral, Santiago del Estero 2829, Sante Fe 3000, Argentina, E-mail: \\ valentinabar.26@gmail.com, cornufranco@hotmail.com.ar
}

\begin{abstract}
:
This study proposes an advanced discrete-event simulation-based tool to support decision-making in the internal logistic design of a packaging line of a multinational brewery company. The selected software, Simio, allows emulating, advising and predicting the behavior of complex real-world systems. The simulation model provides a 3D interface that facilitates verification and validation. In this work, the designed model is used to understand the dynamic interactions between multiple factors and performance measures including both material-handling and inventory systems and to define necessary quantities and/or capacities of resources for a future can packaging line. Based on the proposed model, a what-if analysis is performed to determine inventory threshold values and other critical variables in order to optimize the configuration of internal logistics in potential scenarios.
\end{abstract}

Keywords: discrete-event simulation, can packaging line, logistics, design

DOI: 10.1515/ijfe-2017-0089

Received: March 14, 2017; Revised: October 3, 2018; Accepted: August 21, 2019

\section{Introduction}

In recent years, the supply chain management concept (that operates at three levels: strategic, tactical and operational) has become one of the main approaches to achieve enterprise efficiency. The constant increase in competition drives companies to reduce cost structures with lower inventories, more effective transportation systems and transparent systems able to support information throughout the supply chain [1]. Particularly, in manufacturing systems, strategic decisions typically concern design problems and resources allocation in the medium/long period and can have a considerable impact on financial issues. Usually, problems at this level may involve contrasting objectives therefore requiring a strong experience (for people involved in the decisionmaking process) as well as advanced decision support tools [2].

In this work, an important argentinian brewery company was selected as case study to face the design of a new can packaging line. This company decided to analyze the strategic decision introducing the can package format into the local market in order to reduce the consumption of the returnable beer bottles in order to face the rising logistic costs associated to this last. Currently, consumers are not used to but beer cans. The main goal is to make savings related to inverse logistic costs involved in retournable bottles and to the total amount of beer transported in the same vehicle. There are more liters of beer in a truck that is full of cans than in one full of bottles. It is worth noting that a change in customer habits must be also pursued by promoting beer cans consumption through strong marketing strategies. This decision necessarily requires an increase of the production capacities or indeed the allocation of new packaging lines.

Hence, the present work accounts for the design of a new can packaging line proposing an advanced discrete-event simulation (DES)-based tool to support decision-making and to ensure the best configuration of internal logistics in different production schemes avoiding additional costs. The scope of the system includes warehouses and material handling.

To address this kind of issue, there are two solution strategies typically used: (1) simulation and (2) mathematical analysis. Seila, Ceric and Tadikamalla [3] highlighted several advantages of using the first strategy rather than the second one. For example, the system under study may be so complex that it requires a complex 
model that cannot be easily described by a mathematical formulation (i. e. a set of equations or inequalities). However, the operations of the model can reasonably be represented by a computer program. The analyst can choose to propose a simplified model, even though unrealistic, or he can decide to use the simulation strategy. Hussein et al. [4] also pointed out that even though in many cases the results of a simulation are a confirmation of the expectations (system performance), the true benefit of simulation stays in the discovery of the unexpected situation or circumstance. In this context, relevant examples involve large-scale models of computer communication systems and production, inventory and distribution systems.

Particularly, manufacturing and material-handling systems provide one of the most important applications of simulation. Simulation has been successfully used as an aid in the design of new production facilities, warehouses and distribution centers. Engineers and analysts have used simulation above all to evaluate the impact of capital investments in equipment and physical facility when changes to material handling and layout have to be proposed. Conversely, managers have found it useful in providing "test drive" before making capital investments, without disrupting the existing systems with untried changes [5]. Generally, DES methods have been adopted to represent the whole real-world process as an integrated form.

In this study, the simulation model, is used to accurately represent future process operation in order to analyze its behavior and find its critical variables, mainly those associated to storage and material handling. The goal is to define and optimize internal logistics resources while ensuring the desired production capacity. Different scenarios have been proposed by varying production schedules, so to aid verification and validation processes.

Although other works have recently used simulation tools to solve similar situations in decision-making processes on existing production processes [2,6-8], this study presents an novel application of a simulation model to aid the design of internal logistics configuration of a non-existing line of drink cans.

The paper is divided into the following sections: (1) methodology, (2) internal logistics system (3) simulation model, (4) verification and validation, (5) scenarios and experimentation and (6) conclusions.

\section{Methodology}

To account for the design problem of a new can packaging line by modeling and simulating, several steps are required so to propose a reliable model that can accurately describe the real system. This real-world case is a peculiar one since the real system does not exist, hence it requires some different stages from those traditionally described in previous works. The following steps were made: (1) information collection, (2) data analysis, (3) conceptual model definition, (4) simulation model developing, (5) verification and validation, (6) scenarios definition and (7) results analysis.

The first step consists in collecting accurate information related to the system under study so to start the comprehension process and to identify every significant component. Different techniques were applied: (1) collection of historical data and daily records, (2) "in situ" observation and time taking, and (3) iterative interviews with staff of all hierarchical levels.

One part of the information obtained is used to fully understand the problem and generate the conceptual model. The conceptual model is used to achieve a sufficient abstraction level of the problem and to define assumptions. The other part of the information is filtered and analyzed to become input data.

The brewery company under study has other plants in the country with similar packaging lines. Then, some information was gathered by "in situ" observation from a plant in which the can packaging line already exists: (1) packaging operation (raw materials with its consumption rates and other secondary tasks); (2) characteristics of line and logistic forklifts (manipulation of pallets, average speed, loading and unloading [L\&U] times of empty-can pallets and full-can pallets); (3) characteristics of trucks that transport empty-can pallets, full-can pallets and inputs (capacities, L\&U times, average time of permanence at docks); (4) quality control procedures and rejection rates of empty cans and (5) final-product pallets and empty-can pallets storage constraints. On the other hand, the new packaging line will be installed in a plant where only beer bottle lines are currently working. In order to model the entire system accurately, valuable information was collected by "in situ" observations from the current plant under study: (1) the plant layout with their available spaces for the can packaging line, temporary stock area, and warehouses for final products and inputs; (2) paths and distances traveled by forklifts and trucks; (3) characteristics of the trucks involved in other lines of the same plant (mainly trucks of inputs and final products) including arrival rates and average time of permanence at docks, and finally (4) characteristics of forklifts considering total quantity, types, corresponding areas, average speed, and expected utilization for other lines.

The following step consists in creating the simulation model based on the gathered information and the conceptual model. Simio, the adopted software, is a simulation modeling framework based on intelligent objects. A 
model is built by combining objects that represent the physical components of the system [9]. These objects are modeled to represent forklifts, pallets of materials, warehouses, packaging lines, trucks, racks, etc. Simio was chosen for its power to represent the system in three dimensions and to model realistic spatial relationships of layout. This results in a user-friendly interface that facilitates model verification and validation.

Once the simulation model is verified and validated, it is used to analyze critical performance variables and to test different scenarios. In the last step, the simulation model is pretended to analyzed three configurations of production schedules, to evaluate system feasibility and to define resources such as the quantity of forklift or stock area capacities.

\section{Internal logistics system}

The packaging sector is related with different sectors of the company, such as logistics, comertial, maintenance and quality control. These sectors perform different tasks simultaneously and depend on each other for proper operation. This work focuses on the operation of two of them: warehouses and internal logistics (material handling). The last one manages raw materials and final products through the plant, using forklifts that belong to three sectors: line forklifts, logistic forklifts and inputs warehouse forklift. High season is usually a critical period due to intense material flows between all sectors. Dispatching final products and truck arrivals are also in charge of this sector.

Warehouses are used to stock final products, raw materials and inputs. The packaging line is an internal client of these warehouses, requesting for raw materials and inputs depending on its need and dispatching final products. Figure 1 presents the main sectors involved in this problem with the flow of materials.

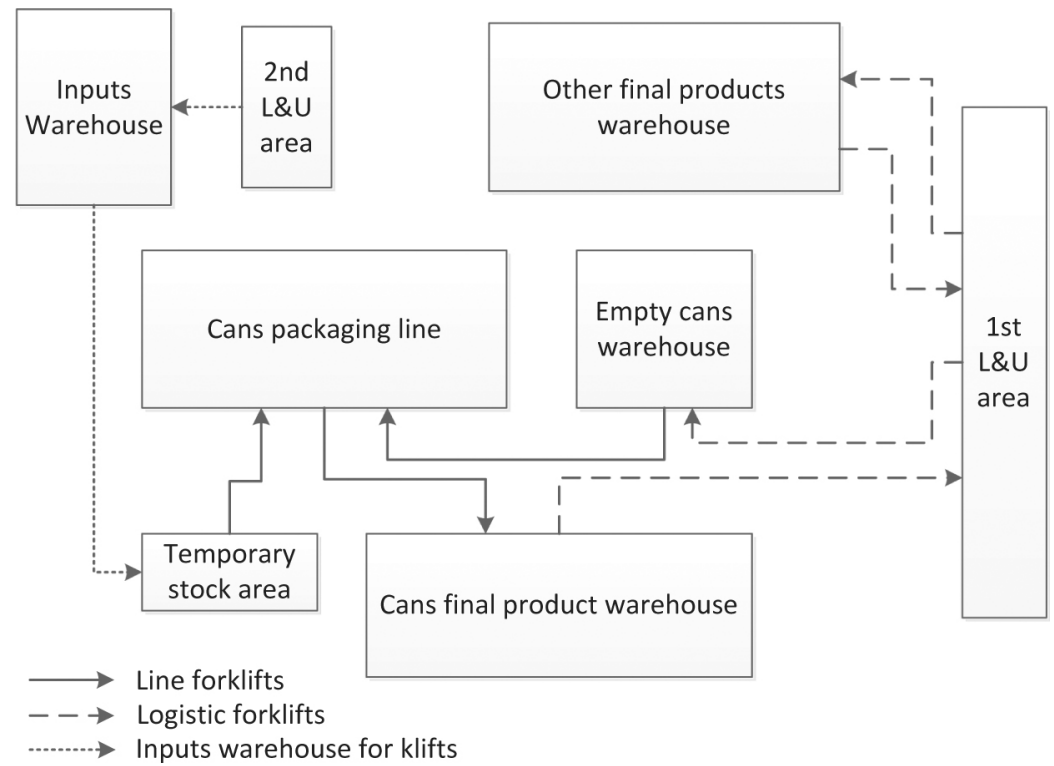

Figure 1: Sectors and material flow involved in internal logistics of the can packaging line.

As shown, the system includes (1) a packaging line, (2) four warehouses, (3) one temporary stock area and (4) two L\&U areas. The lines indicate the flow of materials transported by different types of forklifts through the system. The components of the system are described below.

\subsection{Forklifts}

In the plant, there are five forklifts related to the system under study: four logistic forklifts and one exclusive forklift for the input warehouse. Furthermore, there are no line forklifts (neither packaging line) yet. All of them have the same speed, L\&U times, but not the same carrying capacities. They also have different work schedules, breaks and tasks depending on the sector they belong to. They perform tasks carrying pallets through the system as it is shown in Figure 1. Table 1 summarizes quantity, capacity and work schedules for each type of forklift.

Table 1: Forklifts characteristics. 


\begin{tabular}{llll}
\hline Type & Total quantity & Capacity (pallets) & Work schedules \\
\hline Logistics & 4 & 2 & Sunday 20 h to Saturday $5 \mathrm{~h}$ \\
Input warehouse & 1 & 1 & Monday $0 \mathrm{~h}$ to Friday $17 \mathrm{~h}$ \\
Line & 0 & 1 or 2 & $24 \mathrm{~h}, 7$ days \\
\hline
\end{tabular}

\subsection{Materials}

There is a wide variety of materials moving through the system. To produce a pallet of final product, ten different inputs are needed, such as empty cans, can lids, cartons, wraps, stickers, ribbons, etc. Most of them are initially packaged in pallets. There are also intermediate materials and scrap traveling through the system.

\subsection{Trucks}

On the one hand, trucks enter into the principal L\&U area to load final products and to unload empty cans. They also make loading and unloading tasks related to other packaging lines. On the other hand, trucks entering to the secondary area only unload inputs to stock them in its exclusive warehouse. Most of the trucks can transport 24 pallets, except for empty-can trucks that can only transport 22 pallets. Depending on the type of truck, there can be different restrictions to enter into the factory, such as time constraints.

\subsection{Packaging line}

The future packaging line is required to work $24 \mathrm{~h}$ a day, 3-7 days a week depending on the season. It has an expected line speed and an expected efficiency (real productive percent of time). A bill of materials (BOM) defines input consumption rates and there is a temporary stock area near the line for immediate supply. In this temporary stock area, we should establish the total capacity and a replenishment frequency for each material. The output of the line also has a maximum capacity of pallets. Forklifts are expected to store final products, feed the line and perform secondary tasks associated to residual input pallets.

\subsection{Warehouses}

There are three principal warehouses of interest in the system: input, empty-can and final-product warehouses. Each of them has a desired security stock level. input warehouse has the same work schedule as its exclusive forklift previously mentioned. On days off, it must ensure that the temporary stock area has enough quantity of materials to avoid interrupting the production. The remaining warehouses are directly related to the packaging line, so they must be available all the time.

\subsection{L\&U areas}

The principal L\&U area has four parking places or docks. Trucks bring and retire materials of all packaging lines sharing these parking places. Concerning the tasks related to packaging line, empty cans pallets are unloaded to be stored in its correspondent warehouse. Only one truck of this type can enter at a time into the L\&U area. An analyst examines the lot of empty cans and decides if the truck is rejected or not. About $5 \%$ of these trucks are rejected (empty cans is a very fragile product). Trucks that arrive to dispatch final product have no entrance restrictions.

The secondary L\&U has a single parking place and most of the tasks performed consist in unloading input pallets for all the packaging lines. The input warehouse forklift is in charge of this area.

\subsection{Problem definition}

Once all components and their interactions are fully understood, different conflicts can be detected. There must be a coordination between all sectors. Variations on the line speed or on its work schedule will directly impact 
on warehouses occupation rates. The line could need to be replenished and to retire final product with variable frequency and will consequently impact on line forklifts utilization. Furthermore, final product warehouse will tend to get full during operational days and to empty when the line is off-shift, and in a similar way, empty-cans warehouse and input temporary stock area occupation rates will vary. To deal with this situation, the number of daily trucks arrivals must increase, both to bring inputs and to dispatch final products. Consequently, logistic and input warehouse forklifts are immediately affected. Moreover, security stock levels should be reconsidered, taking into account capacity limitations.

This work analyzes the possibility of getting the desired speed and work schedules without collapsing the system. Actual resources and the infrastructure in the plant under study are combined with a can packaging line of another plant with many adaptations to fix it according to the company plan. Truck arrivals must be designed according to final product expected sales volume and to guarantee certain stability in warehouses occupation. Security levels will be set according to line speed and to support a desired number of productive days. The temporary stock area must be dimensioned according to desired replenishment frequency. An optimal quantity of forklifts must be proposed. The parking places will be evaluated to determine if they can deal with the amount of trucks entering into the system. The simulation model must give enough information to make this set of decisions.

\section{Simulation model}

Once the system is completely understood, the next step is to develop the simulation model. Simio makes modeling easier by providing a new object-based approach. Objects represent the physical components in the system such as workstations, conveyors and forklift trucks in a manufacturing facility. Object-based modeling is a very natural and simple approach to simulation modeling [10]. The developed model uses a factory scale plan with representative distances. The following subsections describe the major components of the model.

\subsection{Model assumptions}

The major assumptions made in the model are listed below:

1. The efficiency of the line is traduced in a daily productive period of time with constant production speed.

2. A generic can product was defined pondering both existing sizes and sell volumes. Then, a pallet of this generic product contains 2,280 cans.

3. Final product pallets are immediately stored in its warehouse and the output of the line has a limited capacity.

4. The temporary stock area can store all pallets that it receives, and it has defined replenishment frequency.

5. Every sector has a defined work schedule.

6. Every truck transports exclusively one type of material.

7. Only trucks transporting empty cans have entrance restriction, one at a time.

8. Trucks have defined capacities according to the material they transport.

9. Forklifts do not fail and drivers do not absence (in real system, there is an additional forklift ready to supply any of them).

10. Trucks are loaded/unloaded using only one forklift.

11. The line forklift does never stop working (drivers take turns to replace).

\subsection{Parameters}

The main input data used in the model is the following:

1. Truck characteristics (capacities, rejection rates, entering restrictions, etc.).

2. Forklift characteristics (capacities, speed, work schedules, L\&U times). 
3. Packaging line speed.

4. Replenishment frequency and quantities of the temporary stock area.

5. BOM matrix.

6. Quantity of pallets that can be accumulated at the output of the line.

7. Secondary task characteristics.

8. Line efficiency (traduced in productive and unproductive daily periods of time).

\subsection{Decision variables}

The following variables represent the main decisions to make in the company.

1. Packaging line schedule.

2. Quantity of forklifts.

3. Truck arrivals.

4. Security and initial stock levels.

5. Restocking frequency to temporary stock area.

\subsection{Output variables}

The following output variables are used to measure the performance of the system:

1. Total production.

2. Quantity of line interruptions because of the lack of inputs.

3. Average, maximum and minimum stock levels of each material in warehouses and in the temporary stock area.

4. Total number of trucks arrived and total number of trucks attended.

5. Forklift and parking place utilizations.

6. Average and maximum stock levels in the output of the line.

Forklifts utilization and stock levels are the main output variables. The analysis of other variables allows detecting if any restriction has not been accomplished or if the system collapsed. The main goal of the model is to achieve a coordinate and stable flow of materials between all sectors because an interruption in the line is not allowed. The output variable "quantity of line interruptions because of lack of inputs" is used to detect if any restriction has not been accomplished or if the system has collapsed. The analysis of this variable allows making decisions about the minimum number of input warehouse forklifts and line forklifts required, the optimal replenishment frequency and the schedule of trucks, so then to adjust those parameters in the model. The model is feasible once the variable "quantity of line interruptions because of lack of inputs" is zero.

\subsection{Simio model}

The computer model was formulated using different objects and setting its properties to adapt them. For further customization, internal logic processes where created and associated these objects. The logic processes allow modeling every necessary detail to create an accurate system representation using events, states, monitors, timers and other elements. Events are logical occurrences at an instant in time that could change the state of the system or of an entity, such as a truck entering at the parking place. These event alerts to other objects that an action has started. A monitor element controls a variable and fires an event when there is a change on it or if it crosses a threshold value. It is used, for example, to control the inventory levels at the temporary stock area and fires a logic process for requesting material replenishment. Finally, a timer fires a set of events at a specified 
hour and can be repeated according a predefined time interval. In the model, a timer is used to control when input pallets that are stored in warehouses must be released for material replenishment and forklifts carry them to the temporary stock area. All these elements can fire internal logic processes in which different actions are modeled. For instance, entrance restrictions, rejection rates, material routes, destinations and requests of materials were modeled with internal logic processes. Appendix A has a small glossary including the major objects of Simio used in the model.

The following subsections describe how the major components of the system were modeled.

\subsubsection{Pallets of materials and trucks}

Pallets and trucks were presented using entities, with priorities assigned to differentiate them. A priority is a numeric property for all entities used to make the ranking rules or the dynamic selection rules to order how entities must move throughout the model. In this case, the priority property is used to differentiate types of pallets and trucks. Internal logic processes are modeled to determine where we must transport a pallet depending on its type or which entity must be created depending on the type of truck that has arrived.

\subsubsection{Forklifts}

Using the vehicle object, forklifts were modeled introducing its characteristics such as speed, capacity, L\&U times, etc. Figure 2 shows trucks, pallets and forklifts of the model. Objects animation facilitates to identify each one. Simulating models provides a 3D interface that enables a system representation in three dimensions and modeling realistic spatial relationships of layout. This user-friendly interface allows the evaluation of the dynamic operation of the system through time and the easy recognition of each element. This is an advantage that strongly facilitates verification and validation stages. It also provides a better visual impression and an additional measure of reality, allowing to present the model to the different stakeholders and let them understand easily the problem. This is one of the main attractive advantages of using simulation instead of mathematical programming or simulation software with less animation development.

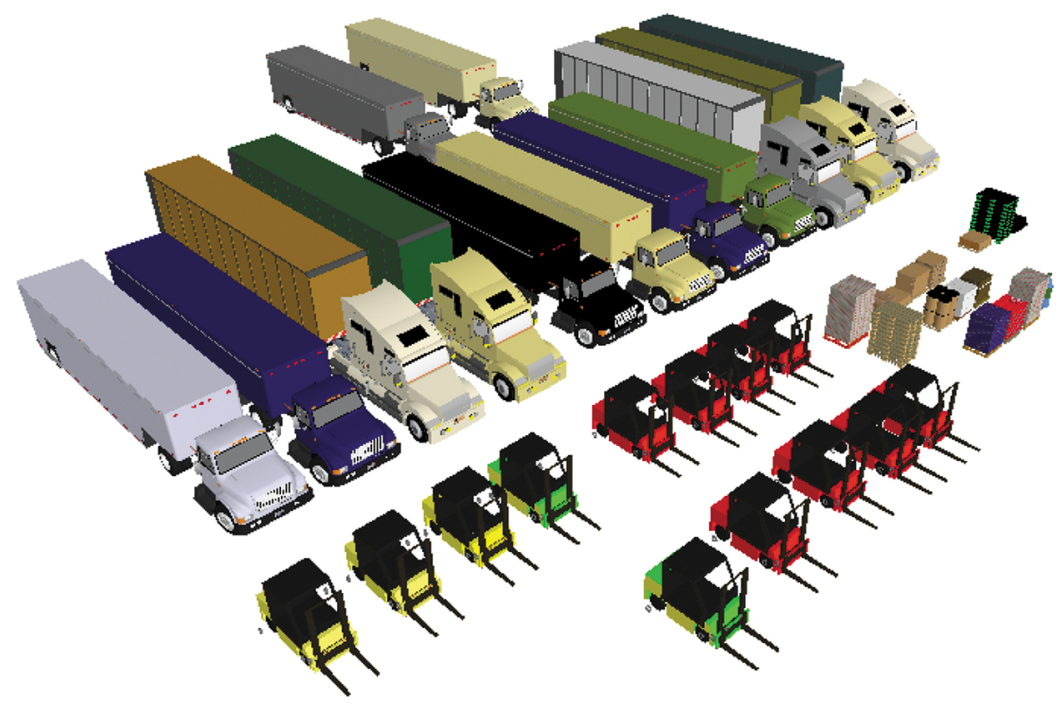

Figure 2: Trucks, pallets and forklifts objects in 3D Simio model.

\subsubsection{Can packaging line}

The packaging line was represented using several objects. The main one is a workstation object. It contemplates consumption and production rates defining a BOM matrix. It monitors with threshold values defined to request pallets of inputs when they are crossed. Figure 3 shows the packaging line at right and the temporary stock area at left. 


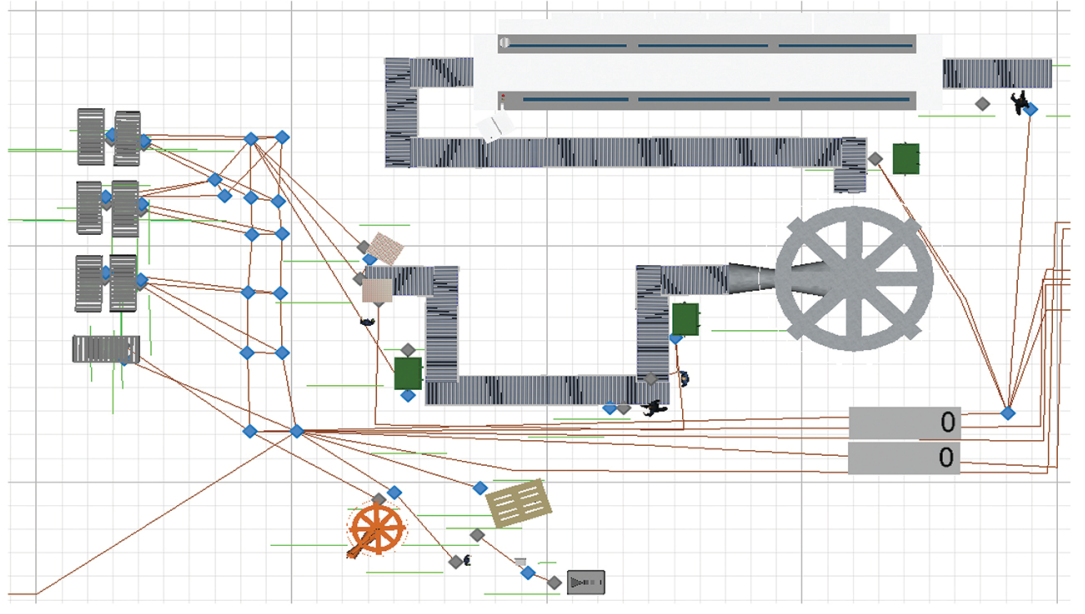

Figure 3: Packaging line and temporary stock area in 2D Simio model.

\subsubsection{Warehouses}

Warehouses were modeled with server objects for each kind of material, customized using internal logic processes to seize pallets until they are requested by another sector and release the exact requested quantity. They also monitor to check stock levels. Figure 4 presents warehouses of empty (left) and final products (right) cans

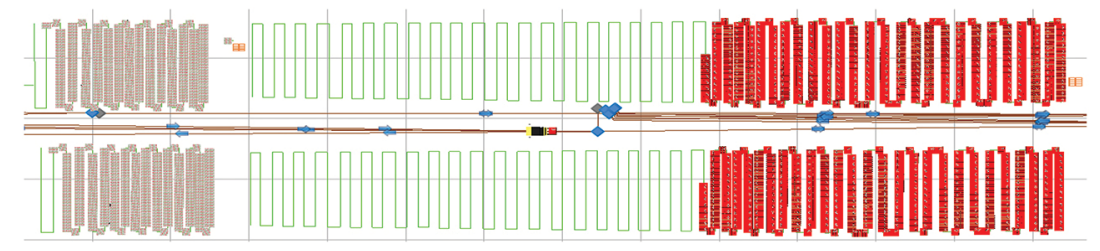

Figure 4: Representation of warehouses of empty and final product cans in the 2D Simio model.

\subsubsection{Temporary stock area}

The temporary stock area was modeled using server objects in a similar way to warehouses; except that it does not have a defined capacity (the simulation will determine it).

\subsubsection{L\&U areas}

They were also represented with server objects, one for each parking place. These sectors use a big quantity of internal processes, in order to model every restriction and rejection rate as well as setting entities destination or requesting warehouses to bring them depending on the type of truck. In Figure 5, at left, there is the input warehouse conformed by several server objects and at right, there is the secondary L\&U area. 


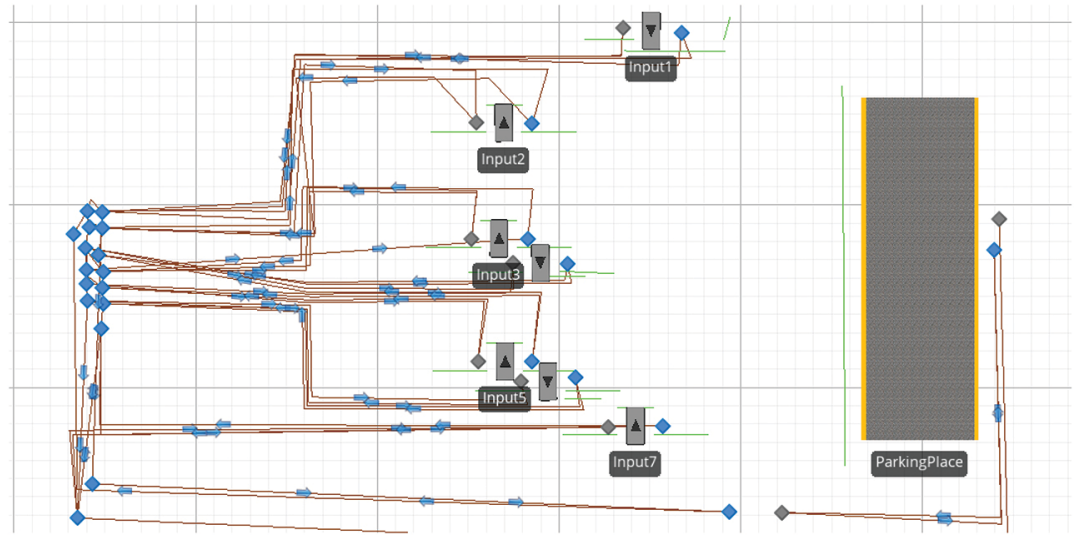

Figure 5: Input warehouse and secondary L\&U area in 2D Simio model.

Figure 6 shows a global view of the animated model. Each sector with its elements can be easily identified, and their operation and interactions can be simultaneously observed.

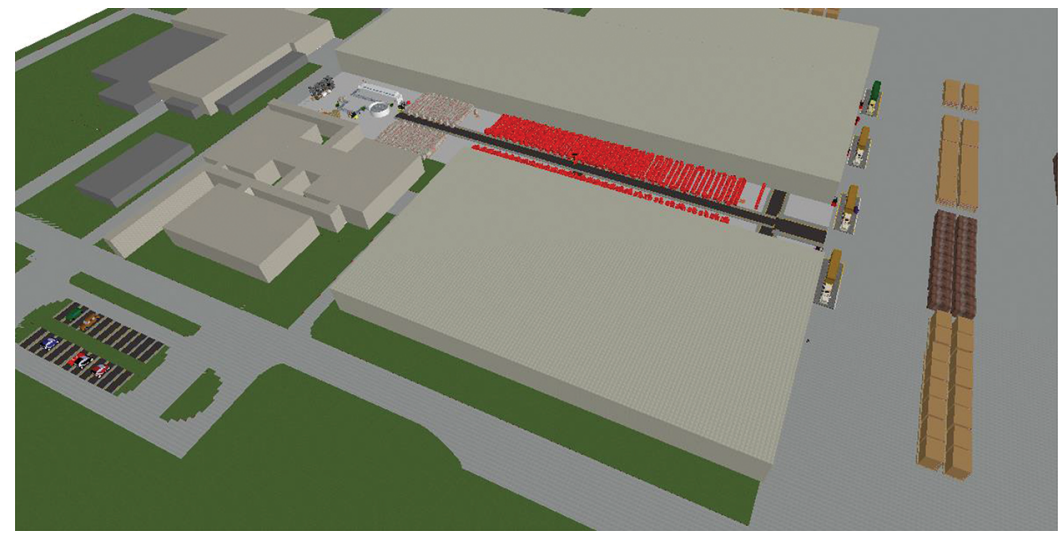

Figure 6: Global view of the 3D Simio model.

\section{ت5erification and validation}

Verification is concerned with determining if the conceptual model with its specifications and assumptions are correctly traduced in a computational representation [11]. During the conceptual model development, the input parameters of all elements such as production and arrival rates and the desired system behavior and constraints were properly determined. The values of input parameters were compared with the values of output variables reported by the simulator in order to evaluate the feasibility and consistency between the simulation behavior and input parameters. As an example, Figure 7 shows a comparison between daily arrivals of empty can trucks and final product trucks required to satisfy the production scheduled in the conceptual model and those arrivals obtained from the simulation of Scenario 2. As well, Figure 8 presents the monthly production rates calculated from the production schedule input parameter and the length of the simulation defined in the conceptual model versus the value of the output variable obtained in the simulation of all scenarios. Similar values prove that the behavior of the computer model is in accordance with estimated values.
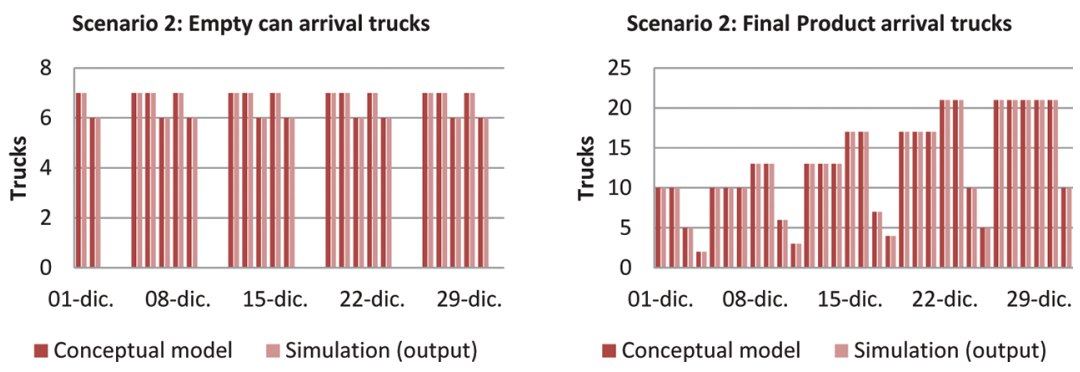

Figure 7: Arrivals of trucks of empty can (left) and final product (right) - Scenario 2 verification. 


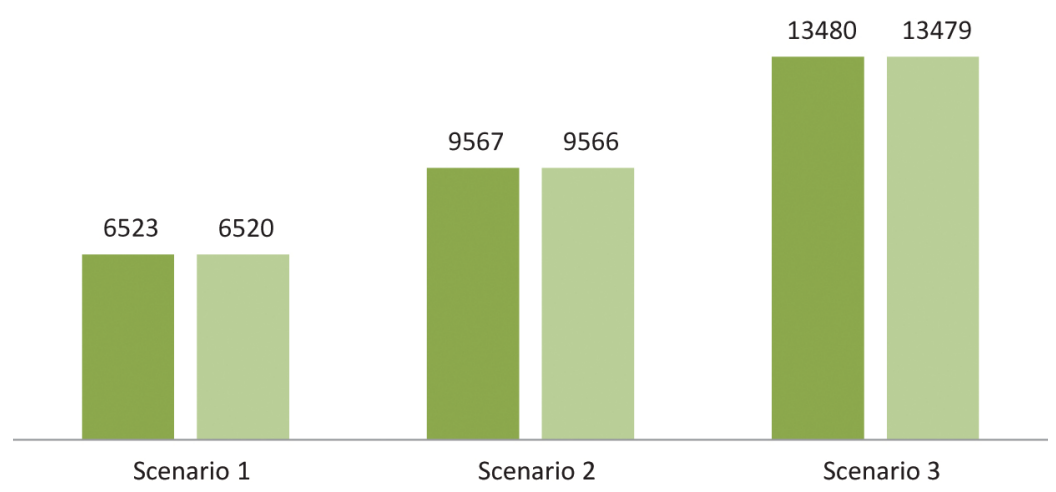

Figure 8: Monthly production verification (pallets).

Afterwards, validation was carried out, which is concerned with determining how closely the simulation model represents the real system [11]. In this step, we made several iterative comparisons between output variables obtained by the simulator and information gathered from the company. The most difficult aspect in this step consists in validating a line which does not exists yet, because there are many aspects that cannot be compared with a real model. Thus, to carry out the validation step of a packaging line that does not exist, we used as reference another can packaging line with similar features that the company already operates in a different plant in the country. Then, validation is performed using other existing packaging lines, such as times related to secondary tasks and input consumption rates. Nevertheless, there are certain aspects that can be validated in the same plant, for example, forklifts times and movements, L\&U times of trucks and secondary tasks. The distances that must be covered by forklifts and trucks in the simulation model were compared with the real scale plant layout provided by the company. Finally, all aspects were discussed with experienced staff from the company. In each iteration, we made necessary changes and adjustments on the model programming in order to achieve the desired values.

\section{Scenarios and experimentation}

As a result of the seasonal demand characteristic of this kind of enterprises, the company wishes to analyze three operational schemes for the can packaging line. The following scenarios were evaluated:

1. Scenario 1: the packaging line works in a cycle within 4 days during the first week, 4 days in the second and 3 days in the third.

2. Scenario 2: the packaging line works 5 days per week.

3. Scenario 3: the packaging line works 7 days per week.

In all scenarios, the line has the same packaging speed and efficiency but different quantity of working days. The main variables affected are (1) packaging line work schedule, (2) the number of daily trucks arrivals and (3) the number of forklifts. Other secondary but not less important affected variables are security stocks and restocking frequency to temporary stock area. The simulation length is a high season month. The following tables and figures show the values of principal decision variables for each scenario. Table 2 presents the optimal number of forklifts defined for each sector and scenario. These are the minimum quantities that prevent collapsing the system or an interruption in the packaging line. Comparing with Table 1, it can be noticed that logistic forklifts seem to be enough to cover all truck arrivals. The line needs at least two forklifts and one of them double (that can carry two pallets) to achieve its requirements. Scenario 1 can work using the actual input warehouse forklift, but other scenarios will need and extra one for proper operation. Otherwise, the temporary stock area does not satisfy the minimum stock levels to feed the line without causing interruptions.

Table 2: Schedule and number of forklifts.

\begin{tabular}{|c|c|c|c|}
\hline $\begin{array}{l}\text { Packaging line work } \\
\text { schedule }\end{array}$ & $\begin{array}{l}\text { Number of logistic } \\
\text { forklifts }\end{array}$ & $\begin{array}{l}\text { Number of input } \\
\text { warehouse forklifts }\end{array}$ & Number of line forklifts \\
\hline Scenario 1 & 4 doubles & 1 simple & 1 simple +1 double \\
\hline
\end{tabular}




\begin{tabular}{|c|c|c|}
\hline Scenario 2 & 4 doubles & 2 simples \\
\hline Scenario 3 & 4 doubles & 2 simples \\
\hline
\end{tabular}

Figure 9 shows the number of arrivals for the three types of trucks per month. These quantities allow dispatching or receiving materials in similar quantities that they are produced or consumed per week. Thus, occupation rates vary weekly but keep cyclical and stable along the month. Nonetheless, final product trucks follow incremental arrivals per week due to a sales politic. In this way, we could optimize warehouses occupation and, with defined security stock levels, we could estimate their capacities. Security stocks of empty cans and final products in their warehouses are equal for all scenarios, because they must cover a certain quantity of productive days to face any eventuallity, independently of the working schedule. They have 687 pallets of empty cans and 5,653 pallets of final product, equivalent to 5 and 13 production days.

\section{Truck arrivals}

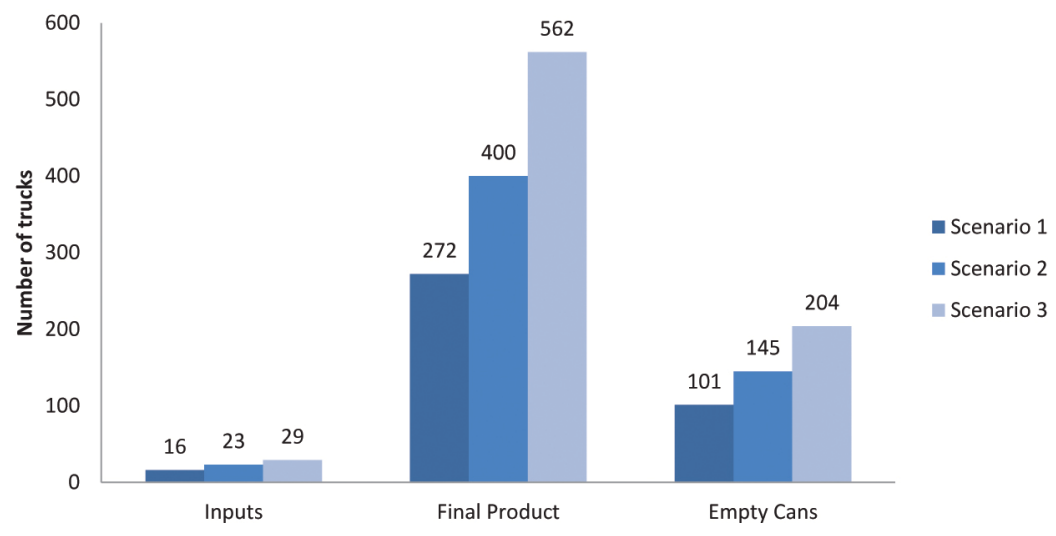

Figure 9: Truck arrivals per month.

Usually, stock peaks are given when the line is working and other sectors are off-shift, or vice versa. Figure 10 and Figure 11 show some output variables of Scenario 3 (7 operational days per week). Scenarios 1 and 2 have a similar behavior. At the top of both of these figures, truck arrivals are shown and, in the bottom, warehouse occupation of their corresponding material is depicted. We can notice the impact that weekends produce on empty-can warehouse (decreasing levels of stock). The reason is that the line continues producing and there are no arrivals of material. Regarding the final product, we can see how warehouses stock levels increase up to the middle of the month and then start decreasing when dispatches levels start increasing. This is a result of the increasing sales volume along the month.

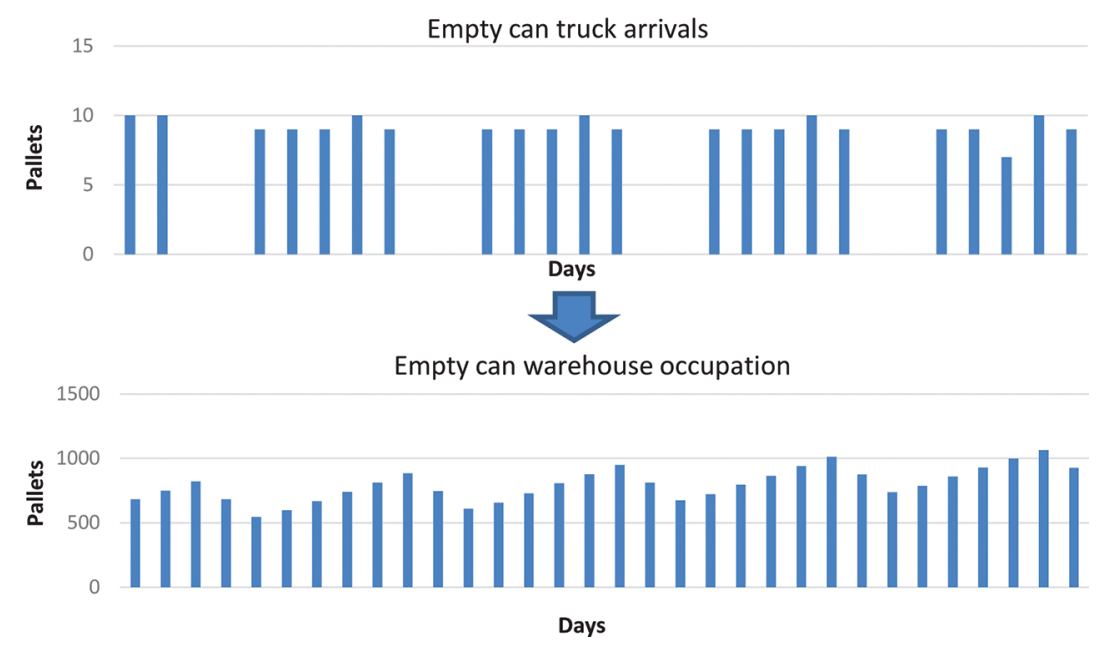

Figure 10: Scenario 3 output variables: daily truck arrivals (above) and warehouse occupation of empty cans (below). 

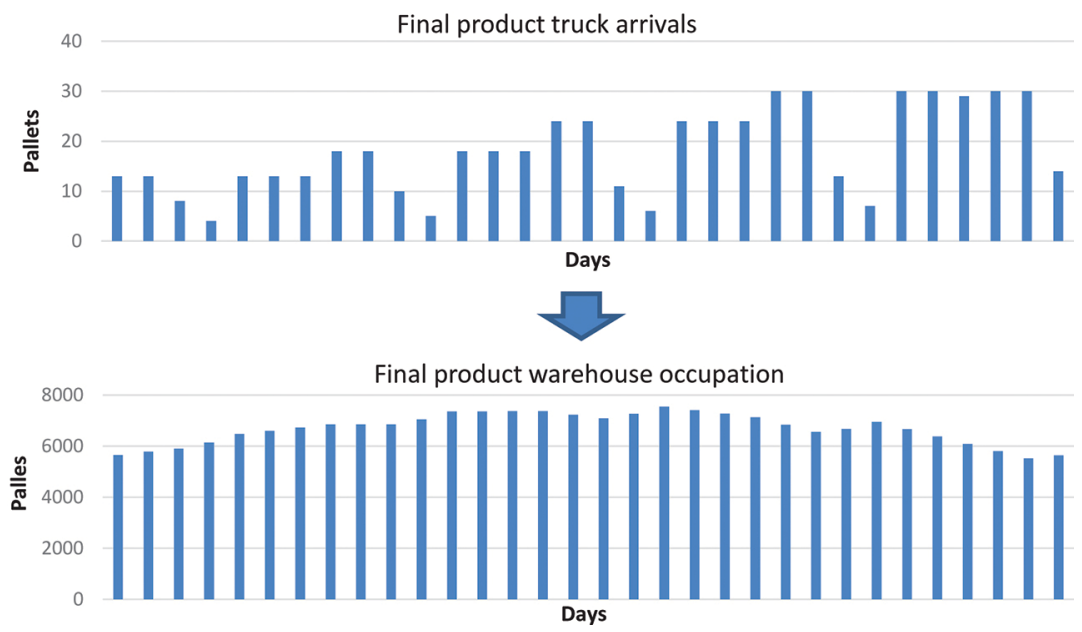

Figure 11: Scenario 3 output variables: daily truck arrivals and warehouse occupation of final product.

Figure 12 and Figure 13 show the remaining stock areas: temporary stock area and input warehouse. In both graphics, the axis on the left refers to occupation (in pallets) of each input represented with color bars, and the axis on the right refers to total occupation (represented with a line). Temporary stock area presents a cyclic behavior with approximately constant occupation. Nonetheless, although input warehouse presents a noncyclic behavior, it is characterized by a stable occupation along the month (without increasing/decreasing tendency). Other scenarios have shown similar behavior.

Temporary stock area occupation

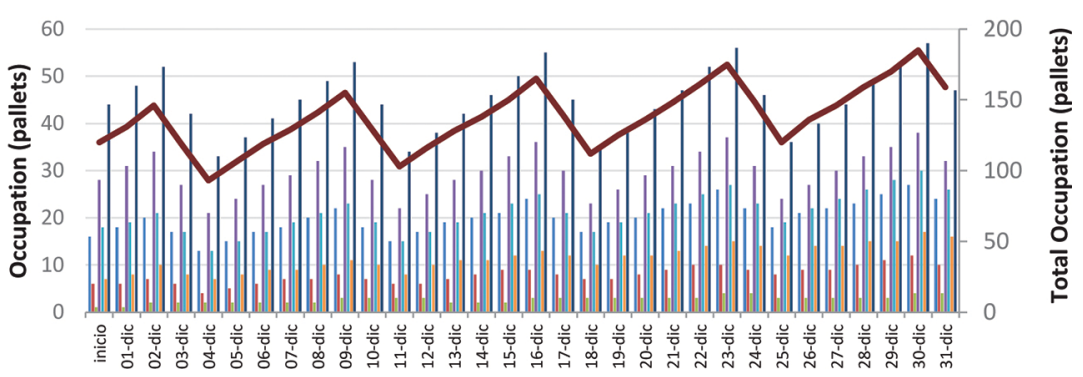

Figure 12: Scenario 3: temporary stock area daily stock levels (pallets).

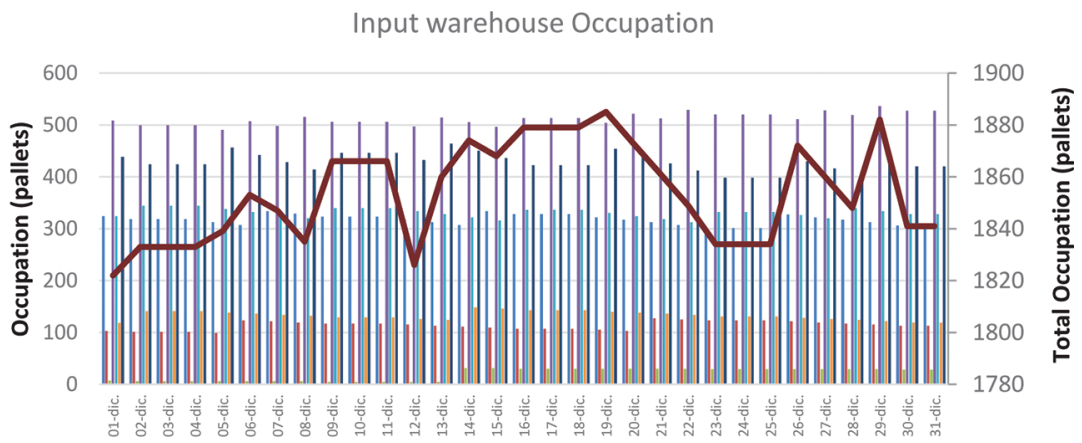

Figure 13: Scenario 3: input warehouse daily stock levels (pallets).

In conclusion, Figure 14 presents maximum and average stock levels in all stock areas. Maximum levels are used to estimate the warehouse capacity. Everyone has its security stock level calculated as a function of working days. The difference between maximum and average levels allows perceiving the degree of variation in the warehouse. This difference is stronger in Scenario 3, because producing on weekends generates and consumes a larger stock quantity that must be liberated or replenished in the same operation schedules than all other scenarios. 

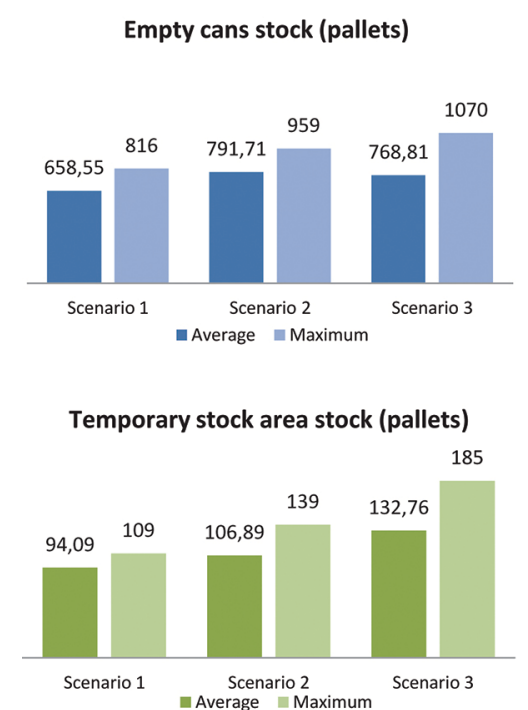

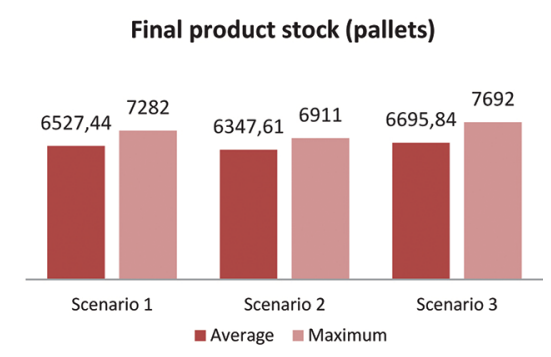

Input warehouse stock (pallets)

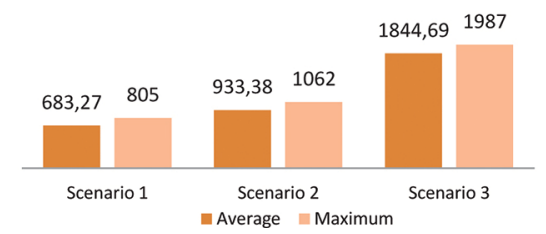

Figure 14: Average/Maximum stock levels of pallets in warehouses.

Finally, Table 3 presents forklift utilization. In the input warehouse, one forklift seems to be enough to cover all tasks. Scenario 2 does not reach proper operation using only one. An extra scenario was tested using only one forklift but extending $2 \mathrm{~h}$ its daily work schedule. Results were satisfactory and this option could be selected instead of adding one extra forklift. Other forklifts do not present important variation on their occupation. Note that the values for outputs are very similar even when monthly production increases. It is important to highlight that every day the line produces the same quantity, but depending on the scenario, there are more working days scheduled; so in the utilization calculation, we must extend the total available time per month (denominator) that a forklift has in his work schedule. Hence, the final three columns give the total operational time per month for each forklift type to have as reference.

Table 3: Forklift utilization.

\begin{tabular}{|c|c|c|c|c|c|c|c|}
\hline \multirow[t]{2}{*}{ Scenarios } & \multirow{2}{*}{$\begin{array}{l}\text { Monthly } \\
\text { production } \\
\text { (pallets) }\end{array}$} & \multicolumn{3}{|c|}{ Forklift utilization } & \multicolumn{3}{|c|}{ Total operational time (h/month) } \\
\hline & & $\begin{array}{l}\text { Logistic } \\
(\%)\end{array}$ & Line $(\%)$ & $\begin{array}{l}\text { Inputs WH } \\
(\%)\end{array}$ & Logistic & Line & Inputs WH \\
\hline 1 & 6,520 & 72.38 & 78.88 & 74.28 & 600 & 360 & 198 \\
\hline 2 & 9,566 & 72.15 & 78.41 & 42.43 & 600 & 528 & 198 \\
\hline 3 & 13,479 & 71.79 & 79.50 & 50.73 & 600 & 744 & 198 \\
\hline
\end{tabular}

In conclusion, a variation in the work schedule of the packaging line can strongly impact on the quantity of final products that must be dispatched and also on raw material requirements. This causes a great increase in the quantity of trucks that must arrive to unload empty cans and to load final product. The variation also affects warehouse capacities but does not affect the required number of most forklifts, except for input warehouse case that needs an extra simple forklift in Scenarios 2 and 3. As there are no can line forklifts yet, two of them (a simple and a double one) are recommended to satisfy production requirements in all scenarios. Maximum stock levels reached in each production scheme determine minimum capacity required to warehouses.

The results obtained using the simulation model help to define which is the ideal production alternative to be chosen depending on the season, and taking into account resources and capacities required for proper operation. Using this tool, other operational policies can be easily simulated and would enable the customer to select them according to the specific requirements.

\section{Conclusions}

The aim of this study was to develop a decision-making support tool to assist the design of internal logistics, including material handling and storage, associated to a can packaging line. To account for this aim, simulation was chosen as research methodology. Specifically, this work introduces a modern DES framework developed with Simio software. The major advantage of this tool is the possibility to emulate future operation policies and 
analyze the behavior of a system which is currently on its design step. Therefore, it allows experimenting with new plant layouts, transport systems, hardware systems, etc. without the need of making early investments on their acquisition or interrupting the normal operation of other lines that will interact with the new one. Thus, it results in a strong tool to perform a what-if analysis that is particularly useful in the design of new systems. The main objects represented were warehouses, forklifts, L\&U areas and packaging line, grounding on real data collected from both the factory under study and another one with a similar packaging line.

The simulation model, after verification and validation, was used to analyze, evaluate and define the best strategy for minimizing costs related to the impact caused by introducing a new packaging line. Three scenarios with different production schemes were evaluated and a set of strategic decisions were listed.

The model developed has some interesting points to highlight. It allowed finding critical points and bottlenecks that were not so obvious to expect, such as the utilization of input warehouse forklifts and logistic forklifts. The model also showed that the first scenario could work without an extra forklift for input warehouse, a condition that according to the company was not possible. It also provided a tool for testing more scenarios with different configurations. These predictions were difficult to point out without a tool representing every detail of a beer can internal logistics system. By examining the context of a drink packaging line, the present work is expected to enhance the knowledge about the use of simulation models in the food industry. In addition, a real world case study was addressed, and the results provided are of immediate interest for the selected company but this analysis tool could also be used to assist decision-making in several food industries to address similar problems.

\section{Funding}

The authors gratefully acknowledge the financial support from CONICET: [Grant Number PIP 112 20150100641] and from Universidad Nacional del Litoral: [Grant Number CAI+D 2016-UNL/PIC 50420150100101LI].

\section{Appendix}

\section{A Clossary}

Path (Figure 15): used to define a pathway between two node locations where the travel time is determined by the path length and a traveler's speed. Entities or vehicles can go through it. Some of its properties are speed, capacity and length.

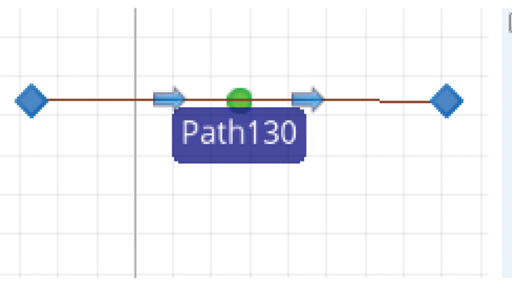

\begin{tabular}{l|l} 
Gravel Logic & \\
Type & Unidirectional \\
\hline Initial Traveler ... & Infinity \\
\hline Entry Ranking ... & First In First Out \\
\hline Drawn To Scale & True \\
\hline Allow Passing & True \\
\hline Ð Speed Limit & Infinity \\
\hline
\end{tabular}

Figure 15: Path module and characteristics.

Server (Figure 16): represents a processing activity in the model. Among its properties, there are processing time, resources needed failures, internal process and events associated.

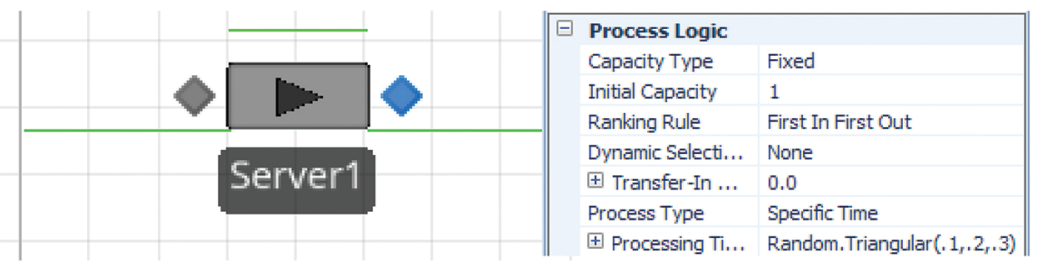

Figure 16: Server module and characteristics.

Sink: represents a final point in the model where entities go to be eliminated.

Vehicle (Figure 17): transports entities from one point to another. It has assigned a pick up and drops off point. Other properties are speed, loading and unloading time and capacity. 


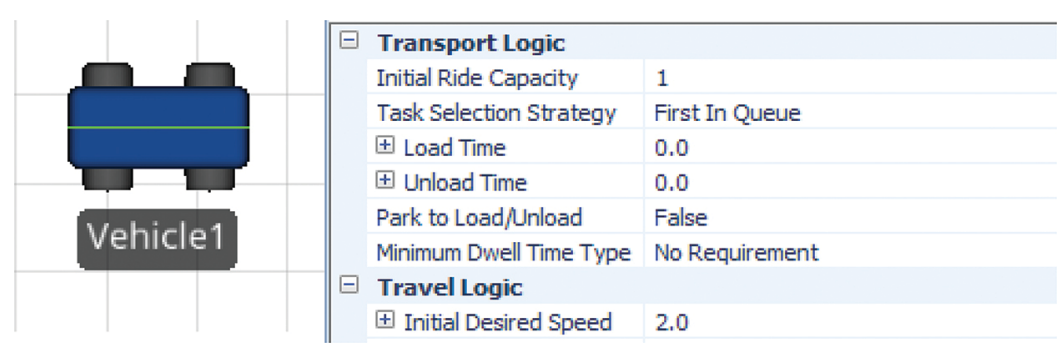

Figure 17: Vehicle module and characteristics.

Workstation: represents a more complex server. It has properties such as setup time and it considers consumption and production of materials based on a BOM matrix.

Internal logic process (Figure 18): A sequence of commands that dictate the behavior of an object. It allows including some tasks into standard modules in order to custom them such as seizing or releasing resources, assigning variables and firing events [6].

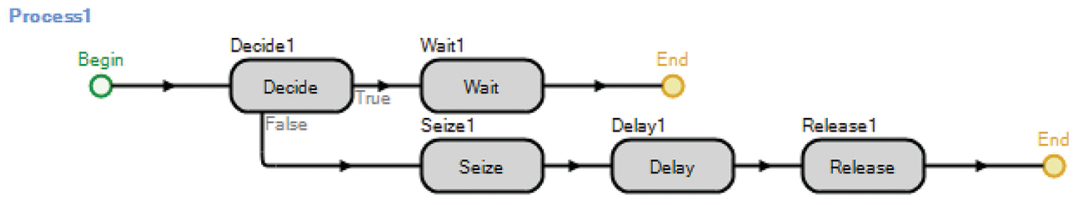

Figure 18: Path module and characteristics.

\section{References}

[1] Pistikopoulos EN, Georgiadis MC, Dua V. Supply chain optimization, part II. Weinheim: WILEY-VCH Verlag GmbH \& Co. KgaA, 2008.

[2] Bruzzone A, Longo F. An advanced modeling \& simulation tool for investigating the behavior of a manufacturing system in the Hazelnuts industry sector. Int ] Food Eng. 2013;9:241-57.

[3] Seila AF, Ceric V, Tadikamalla P. Applied simulation modeling. USA: Brooks/Cole Thomson Learning, 2003.

[4] Hussein WB, Kecker F, Mitzscherling M, Becker T. Computer modelling and simulation of bakeries' production planning. Int] Food Eng. 2009;5(2):1-14.Article 8.

[5] Banks ], Carson JS, Nelson BL, Nicol DM. Discrete-event system simulation. USA: Pearson Prentice Hall, 2005.

[6] Achkar VG, Picech LS, Méndez CA Modeling, simulation and optimization of logistics management of a cans packaging line. In: Proceedings of the 27th European Modeling \& Simulation Symposium. September 2015:395-402.

[7] Aguirre AM, Müller E], Seffino SE, Méndez CA Using an advanced discrete-event simulation framework to productive capacity management of a car-parts factory. In: Proceedings of the 20th European Modeling \& Simulation Symposium. September 2008:159-68.

[8] Basán NP, Cóccola ME, Méndez CA Conducting experimental design and optimization of the system configuration and operation of an innovative car rental business. In: Proceedings of the 27th European Modeling \& Simulation Symposium. September 2015:166-71.

[9] Thiesing R, Watson C, Kirby ], Sturrock D. SIMIO Reference Guide. SIMIO LLC, 2015.

[10] Pedgen CD An introduction to Simio for Begginers. Available at: http://www.simio.com/resources/white-papers, 2009.

[11] Law A. Simulation modeling and analysis. New York: McCraw-Hill, 2007.

Supplementary Material: The online version of this article offers supplementary material (DOI:https://doi.org/10.1515/ijfe-2017-0089).

\section{Bionotes}

Victoria G. Achkar is an industrial engineer and PhD student at the National Scientific and Technical Research Council (CONICET). Her research interests include hybrid simulation \& optimization tools for logistic management of complex production and distribution processes of industrial interest.

Valentina Bär is an advanced industrial engineering student conducting research in optimization and simulation tools for production planning and scheduling of automated production systems. 
Franco Cornú is an advanced industrial engineering student conducting research in optimization and simulation tools for production planning and scheduling of automated production systems.

Dr Carlos A. Méndez is a titular professor of Industrial Engineering at Universidad Nacional del Litoral (UNL) in Argentina as well as a senior researcher of the National Scientific and Technical Research Council (CONICET) in the area of Process Systems Engineering. He has published over 200 refereed journal articles, book chapters and conference papers. His research and teaching interests include modeling, simulation and optimization tools for production planning and scheduling, vehicle routing and logistics. His group's web page is http://servicios.intec.santafe-conicet.gob.ar/grupos/capse/. 